\title{
Educação a distância na sociedade de controle
}

\section{Education in the distance on society of control}

\section{Flávia Cristina Silveira Lemos*}

Professora Adjunta em Psicologia Social do IFCH da Universidade Federal do Pará UFPA, Belém, PA, Brasil

\begin{abstract}
RESUMO
Pretende-se neste artigo realizar uma interrogação das novas tecnologias na educação, especialmente, as designadas como "ensino à distância", que são oferecidas através de ambientes virtuais em plataformas na internet, com franca expansão, no Brasil, sendo difundidas por muitas universidades públicas e privadas atualmente. Problematizamos esta modalidade de educação a partir das análises de Foucault sobre biopolítica, de Deleuze sobre as "sociedades de controle" e de Virilio a respeito do controle político no capitalismo via gestão da velocidade. Afirmamos que a velocidade da gestão da informação e sua transformação em mercadoria vendida por empresas "enxutas" após consultarem especialistas de "marketing" é uma estratégia de controle em ampla difusão, veiculando um ensino técnicoinstrumental para os endividados de informação ao longo de toda a vida.

Palavras-chave: Educação, Capitalismo de especulação, Sociedades de controle, Velocidade e política, Ensino à distância.
\end{abstract}

\begin{abstract}
The intention of this article is to investigate the new technologies in the field of education, in particular the idea of "long distance education", offered through expanding Internet platforms, which, in Brazil, are strongly influenced by public and private universities. We discuss these modalities of education based on the analysis of Foucault and Deleuze on "control societies", and that of Virilio on the political control of capitalism via the management of velocity. We claim that the velocity of management of information and its commoditization sold to "lean" companies after consulting experts on marketing is a strategy of control and broad diffusion which conveys a technical-instrumental education for those who lack information for their lives.
\end{abstract}

Keywords: Education, Capitalism of speculation, Societies of control speedy and policy, long distance education.

Busca-se interrogar a expansão do ensino à distância e a afirmação de sua eficácia como dispositivos de flexibilização da educação sob a égide de uma sociedade de controle. Também é realizada uma crítica à mercantilização da educação escolarizada operada no capitalismo global através de estratégias de marketing. As discussões de Michel Foucault sobre o neoliberalismo, assim como as de Gilles Deleuze a 
respeito das sociedades de controle e as contribuições de Paul Virilio, analisando as relações entre velocidade e política são instrumentos utilizados para pensar o acontecimento expansão da educação à distância.

\section{O neoliberalismo alemão e norte-americano para Michel Foucault}

Antes de entrar na temática da educação à distância diretamente, realiza-se uma introdução, neste tópico, das análises de Foucault sobre o neoliberalismo, já que este é o contexto em que esta modalidade de educação se expande.

Foucault (2008), em "Nascimento da biopolítica", abordou os efeitos das transformações do liberalismo em neoliberalismo (neoliberalismo), como resposta à crise mundial de 1929, que foi potencializada a partir de uma segunda crise econômica, na década de setenta.

O neoliberalismo alemão, para Foucault (2008), demandou pedidos de liberação de preços, limitando o poder do Estado tanto na intervenção econômica quanto na política, ampliando, assim, as liberdades dos cidadãos com a intensificação de responsabilidades, paralelamente. Tratava-se de assegurar uma liberdade, sobretudo, no domínio da economia, produzindo, então, um Estado econômico protetor da propriedade privada, em que não perderia sua legitimidade desde que assegurasse a liberdade de concorrência de seus parceiros econômicos. O Estado deveria ser vigiado pelo mercado, que passaria a ser uma espécie de termômetro das políticas de regulação estatais.

Foucault destaca que há várias diferenças entre o liberalismo de um Estado de bem-estar protecionista e intervencionista e o neoliberalismo, cuja característica é "uma formalização geral dos poderes do Estado e da organização da sociedade a partir de uma economia de mercado [...]" (2008, p. 160). O autor ainda ressalta que, no caso dos discursos do neoliberalismo alemão, o que estava em jogo não era a ampliação do sistema de trocas e sim da concorrência, no plano da desigualdade e não da equivalência. $O$ governo não deixa de existir, sendo que sua nova tarefa é governar para o mercado e estabilizar preços sempre.

O Estado deverá criar a moldura institucional para a livre concorrência, não devendo garantir o pleno emprego e sim o poder aquisitivo por meio de uma política de crédito contínua, incentivando o chamado empreendedorismo e descontos diversos, com reduções moderadas de impostos. Inicia-se uma promoção massiva de investimentos. O desempregado passa a ser visto como alguém em trânsito entre uma atividade pouco rentável ou nada rentável até uma mais rentável. No entanto, para facilitar a economia de mercado, o Estado deveria continuar a controlar a população em seus 
deslocamentos, induzir aperfeiçoamentos técnicos, gerir os processos e estabelecimentos de ensino para lidar com as técnicas, fazendo intervir a legislação para incentivar a disponibilização de recursos diversos, tanto econômicos quanto os denominados naturais, fazendo com que tudo funcione como um mercado em que cada um deve gerir os recursos ou criar os recursos para tornar-se um investidor (FOUCAULT, 2008).

Ora, é a intensificação da liberdade de concorrência no chamado mercado da educação uma das questões que produzem uma demanda pela educação à distância já que a competição acelerada cria uma necessidade de formação mais rápida e mais técnica, por uma via que não seja a presencial que geraria perda de lucros pelas empresas. A educação presencial tem um custo econômico bem mais alto para as universidades particulares em termos de manutenção de uma estrutura física para uma grande parcela de estudantes. Além do que, com instalação de uma plataforma de ensino na internet, por exemplo, os custos são bem menores e se atinge um número maior de alunos em função da diminuição dos valores das mensalidades a serem pagas.

Sabe-se que o Estado é um dos indutores de políticas de expansão da educação à distância e, deste modo, assegura e protege o setor privado, incentivando o uso da tecnologia no ensino e gerindo a concorrência entre as "empresas" que oferecem a educação à distância a partir da criação de parâmetros para seu funcionamento e difusão. A ampliação deste setor de ensino vem sendo defendida pelo Brasil como modo de gerar oportunidades por meio de políticas compensatórias na educação de jovens e adultos, por exemplo, alcançando um segmento que foi excluído do sistema tradicional de ensino público.

Para Foucault (2008), o neoliberalismo alemão criou e postulou uma política de acesso aos bens de consumo pela via da garantia de um mínimo vital por meio de políticas sociais compensatórias, protegendo os indivíduos frente aos riscos diversos. No entanto, o Estado vai impulsionar políticas em que cada um tenha rentabilidade para custear os serviços por si mesmo!

[...] Vai-se pedir à sociedade, ou antes, à economia, simplesmente para fazer com que todo indivíduo tenha rendimentos suficientemente elevados de modo que possa, seja diretamente e a título individual, seja pela intermediação das sociedades de ajuda mútua, se garantir por si mesmo contra os riscos que existem, ou também contra os riscos de existência, ou também contra essa fatalidade da existência que são a velhice e a morte, a partir do se constitui sua própria reserva privada. Ou seja, a política social deverá ser uma política que terá por instrumento, não a transferência de uma parte da renda ao outro, mas a capitalização mais generalizada possível para 
todas as classes sociais, que terá por instrumento o seguro individual e mútuo, que terá por instrumento enfim a propriedade privada. (FOUCAULT, 2008, p. 197)

Esta política econômica é um projeto de sociedade em que o que está sendo acionado não é a produção do homem consumidor e sim do homem empresário, em uma dinâmica concorrencial. A sociedade empresarial subjetiva, o homo oeconomicus. Passa-se a fomentar as pequenas empresas, o pequeno comércio, em cidades de médio porte, apóia-se a descentralização da gestão e dos locais de moradia, incentivando também as pequenas produções no campo e artesanais. Foucault (2008) chega a afirmar que está se difundindo a forma empresa para toda a sociedade em sua multiplicidade e diferenciação amparadas por uma lógica da arbitragem jurídica sem igual. Ele conclui que a sociedade empresarial é a sociedade judiciária, em que o enquadre jurídico regula o regime de propriedades, de contratos, de falências, o estatuto das associações profissionais, salvaguardando a liberdade das transações. "O Rule of Law e o Estado de direito formalizam a ação do governo como um prestador de regras para um jogo econômico em que os únicos parceiros e os únicos agentes reais devem ser os indivíduos ou, digamos, se preferirem, as empresas." (FOUCAULT, 2008, p. 238). Ora, o que tem se instalado, deste modo, é uma crescente demanda por lei e ordem.

Já o neoliberalismo americano, constituído nos Estados Unidos, se diferencia em alguns aspectos do alemão, surgindo como crítica à política do pós II Guerra Mundial de planificação e keynesiana de programas econômicos e sociais de seguridade e proteção/ intervenção. Configura-se, neste enfrentamento, uma estratégia embasada na designada teoria do capital humano, desenvolvendo-se uma ciência econômica em que se foca o comportamento humano, analisando-o, calculando-o e programando-o. O trabalho passa a ser entendido não mais enquanto uma força vendida pelo operário diante de uma demanda de oferta, mas de um sujeito econômico ativo, que não busca um salário, mas uma renda. Neste sentido, o trabalho "[...] comporta um capital, isto é, uma aptidão, uma competência [...]" (FOUCAULT, Op. Cit., p. 308) e, a renda "[...] é simplesmente o produto ou o rendimento de um capital. E, inversamente, chamar-seá 'capital' tudo o que pode ser, de uma maneira ou de outra, uma fonte de renda futura. [...]" (FOUCAULT, Op. Cit., p. 308).

Os fatores físicos e psicológicos podem ser classificados em prol da ampliação deste capital enquanto um conjunto de habilidades inatas e adquiridas que poderão ser expandidas ao máximo e infinitamente, sempre mais, pela via da educação e de novas tecnologias de gestão do capital humano e de uma série de vários investimentos afetivos, culturais, sociais, familiares, em que é “[...] o próprio trabalhador que 
aparece como uma espécie de empresa para si mesmo [...]" (FOUCAULT, 2008, p. 310).

Este homem ambiciona ser um produtor ativo de sua satisfação por isto investe sem descanso. Nesta gerência de supostas habilidades e competências em prol da intensificação da renda e da satisfação pela potencialização do capital humano, a denominada formação continuada, que se transformou em uma formação ao longo de toda a vida, ganha um lugar de destaque central nesta sociedade empresarial. "[...] Quer dizer, é claro, fazer investimentos educacionais. [...]" (FOUCAULT, Op. Cit., p. 315).

Tudo ganha caráter de investimento, o tempo dos pais dedicado aos filhos, as atividades extra-educativas no âmbito cultural, o lazer; os cuidados médicos-psicológicos, a mobilidade e os intercâmbios/ deslocamentos; a tentativa de inovar sempre por meio do progresso técnico; a decisão de com quem se casar e ter filhos, quando e como, analisando os ganhos e os prejuízos deste contrato; o governo de um possível desenvolvimento humano e de seu estímulo pelas várias formas à disposição da sociedade que passa a realizar um planejamento de empreendimentos de si; a utilização de tecnologias genéticas para expandir habilidades biológicas; o planejamento familiar; o controle de natalidade e longevidade para efetuar e adquirir planos de saúde e seguros vários, em uma perpétua transação e aferição de custos/benefícios das ações de cada indivíduo, da população e do Estado (FOUCAULT, 2008).

A administração racionalizada da vida se intensifica em nome da sociedade guiada pela lógica econômica. Cada detalhe de nossas vidas passa a ser gerido a partir de uma rede capilar e sutil de mecanismos de controle em meio-aberto que se espraiam por inúmeros processos de normalização (DELEUZE, 1992a).

O direito só punirá o intolerável, enquanto a normalização se estreita como nunca e, segundo Foucault (2008), toda uma tecnologia de controle de conduta em nível de uma escola ambientalista da psicologia denominada "Análise do comportamento" ou "Teoria do comportamento" será utilizada como verdadeiro programa não só educativo, mas também político, jurídico e econômico.

Curiosamente, toda uma literatura ambientalista da educação com pinceladas cognitivistas está na base da criação e difusão dos chamados "ambientes instrucionais", ferramenta da educação à distância que define o ensino como instrução técnica controlada por tutores da aprendizagem dirigida.

Ora, este novo homem é convidado a ser obediente aos seus interesses do capital e passa a buscar sua satisfação como consequência dos investimentos que realiza, por isto, obedece com docilidade em resposta às induções de um meio que o estimula e gerencia seus comportamentos instrutivamente. Ainda assim, este sujeito alvo de governo dos outros no plano de suas condutas é 
alguém que escolhe, opina e cria projetos, em certo espaço de liberdade para que aceite aderir a esta plataforma ambientalista e econômica do empreendedorismo, baseado na teoria do capital humano, não sendo governado pelos outros somente, porém, efetuando uma gerência de si também.

Foucault ressalta que o sujeito de direito é o sujeito do contrato, onde pode resolver se juridicamente o contrato ressalva ou não seus interesses, mas, para isto, precisa operar sempre um cálculo destes interesses e dos danos que poderá sofrer. Concluindo, "[...] deve-se governar com a economia, deve-se governar ouvindo os economistas [...]" (FOUCAULT, 2008, p. 389).

Porém, Foucault (2008) ainda alerta que o Estado também passou, neste processo de mudança, a ser tutelado por uma nova tecnologia, a sociedade civil comunitária, objeto histórico que tem sido essencializado por muitos movimentos sociais e que tem emprestado uma racionalidade para as práticas governamentais, nas últimas décadas. A sociedade civil se torna um ente que converge interesses. "[...] Uns vão dar opinião. Outros vão dar ordens. Uns vão refletir, outros vão obedecer. [...]" (FOUCAULT, op cit., p. 412).

Dessa forma, ainda que muitos aprovem ou critiquem alguma situação ou pauta, e cheguem a decidir juntos, vão examinar, consultar e deliberar em porções seletas, o que assinala para a importância do conjunto de especialistas e/ou representantes da chamada sociedade civil organizada que elege e/ou aceita seus delegados, em geral, participantes de ONG's, fundações, associações que levantam a bandeira do coletivo e dizem que vão falar "em nome de". Diversos cursos à distância vão ser oferecidos por meio de parcerias entre governo e entidades não-governamentais como forma de reduzir situações nomeadas de vulnerabilidade social como política designada como desenvolvimento sustentável includente, por exemplo: as ações chamadas de responsabilidade social.

\section{Gilles Deleuze e a análise deste novo capitalismo global, neoliberal e de controle no campo da educação}

Os mecanismos de controle emergentes seriam imanentes ao redimensionamento do capitalismo contemporâneo globalizado que pretende tudo englobar, em uma rede fina, em um espaço liso e aberto, tendo como importantes dispositivos de controle: a mídia, a informática e a biotecnologia (PELBART, 2000).

Para Deleuze (1992b), a sociedade atual seria uma "Sociedade de Controle", caracterizada por uma intensificação do controle em meioaberto; da extensão dos processos de comunicação, sobretudo, através da mídia e de seus dispositivos de homogeneização da cultura e dos modos de existência; da ampliação da gestão empresarial inundando todas as esferas da vida através do 
"marketing", inclusive no campo educacional, em que as informações teriam sido mercantilizadas.

A educação escolarizada, nas "sociedades de controle", é transformada em uma empresa que vende serviços a um consumidor supostamente exigente. Quem adquire informação tem pressa de consumir uma mercadoria de fácil acesso e que pode ser engolida rapidamente, sendo capitalizada através da negociação de certificados e diplomas que ganham status de investimento, em um mercado ávido por currículos e por um capital denominado imaterial.

Inclusive, atualmente, assessorias de "marketing" têm sido contratadas, no Brasil, por instituições de ensino superior e por universidades privadas para "enxugar" suas despesas e torná-las competitivas no mercado financeiro. Algumas universidades brasileiras já pensam em vender suas ações nas bolsas de valores.

Para fazê-lo, as supostas empresas do ramo da "educação" contratam estas assessorias de marketing, que promovem uma auditoria detalhada nos modos de funcionar e operar de uma instituição. Após o "diagnóstico organizacional", são disparadas as práticas de reestruturação organizativa que, em geral, começam com o descarte em massa de funcionários antigos e professores doutores, com a precarização do trabalho docente de quem não é desligado e a criação de controles finos para reduzir o que chamam de despesas e obstruções da livre comercialização da educação.

Também são fabricadas campanhas publicitárias para vender as imagens dos serviços e dos produtos da empresa, associadas ao sucesso e à competência técnica, sendo vendidas de forma rápida e com valor de uma grife. O nome da universidade torna-se uma marca comercializada e vinculada a um estilo de vida de sucesso conquistado de modo pragmático, veloz, sem impedimentos quaisquer.

\begin{abstract}
Não existe, talvez, melhor exemplo da extensão do mercado a novas áreas da vida social que o campo da educação. [...] Nessa nova situação, as pessoas são pressionadas para se envolver em novas atividades que são amplamente definidas por novas práticas discursivas tais como marketing, publicidade e gerência. Essas mudanças incluem recodificações discursivas tanto de atividades quanto de relações: o resultado é que os alunos e aprendizes se tornam "consumidores" ou "clientes" e os cursos se tornam "pacotes" ou "produtos". (PETERS, 2002, p. 212)
\end{abstract}

A mídia se torna um dispositivo de produção e circulação das campanhas publicitárias de universidades e escolas que pretendem ser reconhecidas não pela pesquisa e pelo pensar, mas sim pela imagem que prometem de ascensão social e econômica rápida. 
Nesta forma de educação-empresa, as novas tecnologias de ensino ganham visibilidade e se tornam a promessa de um ensino sem dificuldades; sem presença espacial em horários definidos; sem professores, que são substituídos por tutores; sem muitas exigências de questionamentos e leitura de livros e textos complexos, pois, nos ambientes virtuais são disponibilizadas apostilas com conteúdos mastigados.

\footnotetext{
[...] a linguagem usada para sustentar essa visão é uma linguagem de "excelência", "inovação, melhoria e modernização", "obter mais com menos", "alfabetização tecnológica", "revolução na informação e nas telecomunicações", "marketing e gerência internacionais", "treinamento de habilidades", "desempenho" e "empresa". (PETERS, 2002, p. 222)
}

As chamadas novas tecnologias da informação, das comunicações alinhadas, sobretudo, pela venda em massa de computadores e pela difusão da comunicação e informação pela internet teriam facilitado a comercialização da educação pela via de ambientes designados como instrucionais, programados por administradores da informação e por negociantes neoliberais. Esta modalidade de educação utilizaria diferentes recursos, como: e-mail, chats, fóruns de discussão, avisos, compartilhamento de arquivos e textos adicionais.

Não se trata de afirmar que a educação à distância é um "mal" em si, mas de problematizar a utilização desta tecnologia paralelamente à desqualificação do ensino presencial. Sendo que o seu uso indiscriminado e generalizado, em uma oferta barata e banalizada do ensino superior e das especializações lato sensu, é o que está sendo questionado como estratégia de mercado neoliberal e de controle dos corpos em meio aberto.

O debate nos fóruns geralmente é enviesado pelas perguntas realizadas e pelas e enquetes lançadas na rede por um tutor com pouca qualificação que lança questões que são rapidamente respondidas em uma consulta rápida da apostila disponível na plataforma. Os textos usados são escritos e preparados especificamente no formato exigido pela empresa que oferta o curso, no estilo de apostilas de síntese de informações.

Há também um controle fino operado na discussão dos fóruns, pois esta fica toda registrada na plataforma com permissão de acesso tanto pelo tutor, quanto pelo estudante e por coordenadores e gestores do sistema virtual.

Esta tecnologia vem sendo utilizada como apoio ao ensino presencial de forma a potencializar o espaço da educação universitária e em nível de pós-graduação, no Brasil; em cursos de capacitação governamentais e privados. Já existia desde a década de sessenta, do século XX, no país, sob forma de apostilas postadas pelo correio e, 
depois, em difusão de rádio para lugares em que não havia acesso ao sistema de ensino tradicional.

A Organização das Nações Unidas para a Educação, Ciência e Cultura (UNESCO), em relatório publicado no Brasil em formato de livro, com o título "Educação para o século XXI: um tesouro a descobrir", em 1999, propõe que todos os países adotem tecnologias que os assessores desta agência multilateral designam como inovadoras na educação, prescrevendo-a como uma política de ensino que deverá ser amplamente difundida, em todos os níveis, propiciando uma formação continuada ao longo da vida, sugerindo a modalidade à distância como importante estratégia a ser utilizada.

Para o leitor ter uma noção da expansão desta forma de ensino, no Brasil, o governo brasileiro publicou a portaria N. 4.059, em 10 de dezembro de 2004 , prevendo que até $20 \%$ da carga horária total dos cursos de graduação, no ensino superior, no país, poderiam acontecer na modalidade semipresencial, com a utilização de atividades realizadas a partir de tecnologias de comunicação remota, em diferentes suportes de informação.

Além deste decreto, foi criada uma secretaria específica de educação à distância pelo Ministério da Educação. Abaixo, pode-se acompanhar o crescimento dos cursos superiores oferecidos à distância, no Brasil, de acordo com dados do Censo da Educação Superior de 2006, em notícia divulgada pela assessoria de imprensa do Instituto Nacional de Estudos e Pesquisas Educacionais Anísio Teixeira (INEP), em 19 de dezembro de 2007:

Os dados mostram um grande crescimento nos cursos de educação a distância. De 2003 a 2006 houve um aumento de $571 \%$ em número de cursos e de $315 \%$ no número de matrículas. Em 2005, os alunos de EAD representavam 2,6\% do universo dos estudantes. Em 2006 essa participação passou a ser de 4,4\%. As demais modalidades também tiveram aumento, menor nas graduações $(8,3 \%$ em número de cursos e $5 \%$ em número de matrículas) e com destaque nos tecnológicos, que tiveram aumento nas matrículas de 34,3\%. (INEP, 2007).

Com as designadas novas tecnologias de telecomunicação, como: a internet, as teleconferências, teleaulas em vídeos/DVDs e as aulas transmitidas por satélite, expandiram-se os cursos à distância, com apoio do Ministério da Educação.

Enfim, as plataformas de ambientes virtuais, na internet, utilizadas recentemente pelos projetos de oferta de educação à distância seriam os apregoados redentores de todos os impedimentos de democratização da educação escolarizada e apareceriam como as salvadoras das mazelas da educação taxada de forma maniqueísta 
como excludente e autoritária pelos vendedores e publicitários de cursos não-presenciais.

Se a educação deve acontecer, agora, ao longo de toda uma vida, ela deveria, para os novos empresários, ser vendida pela internet de modo rápido e com poucos entraves aos lucros exorbitantes demandados pelos investidores deste negócio chamado "sociedade da informação". Esta sociedade se aproxima do que Deleuze (1992a; 1992b) denominou "sociedades de controle".

Certamente, não se deixou de falar da prisão, da escola, do hospital: essas instituições estão em crise. Mas se estão em crise, é precisamente em combates de retaguarda. O que está sendo implantado, às cegas, são novos tipos de sanções, de educação, de tratamento. Os hospitais abertos, o atendimento a domicílio, etc., já surgiram há muito tempo. Pode-se prever que a educação será cada vez menos um meio fechado, distinto do meio profissional - um outro meio fechado -, mas que os dois desaparecerão em favor de uma terrível formação permanente, de um controle contínuo se exercendo sobre o operário-aluno ou 0 executivouniversitário. Tentam nos fazer acreditar na reforma da escola, quando se trata de uma liquidação. Num regime de controle nunca se termina nada. [...] (DELEUZE, 1992a, p. 216)

[...] O princípio modulador do "salário por mérito" tenta a própria Educação nacional: com efeito, assim como a empresa substitui a fábrica, a formação permanente tende a substituir a escola, e o controle contínuo substitui o exame. Este é o meio mais garantido de entregar a escola à empresa (DELEUZE, 1992b, (a ou b?) p. 221)

As tecnologias digitais e a expansão das telecomunicações teriam produzido a ampliação dos mecanismos de controle mais sutis e modulares, organizada em fluxos contínuos, sendo a sociedade marcada por uma transição do capitalismo de produção para um capitalismo de especulação, que passou a funcionar, em sua versão neoliberal, como fluxo de capital instantâneo flexível. Nesta nova realidade, as relações também se tornam fluídas e moduladas pelo descarte e rapidez. A demanda por mecanismos de gestão em todas as esferas da vida se intensifica através das técnicas de gerência e venda de serviços: escola, empresa, saúde (DELEUZE, 1992b).

Os controles seriam modulações contínuas, em que a flexibilidade é requisitada, tudo se torna fluido e líquido, podendo ganhar formas diversas e provisórias. A convocação da mudança permanente é um efeito das "sociedades de controle". Deleuze (1992a) chega a afirmar que nas "sociedades de controle" não se termina nada nunca, viveríamos endividados em todos os campos, como na educação e nos financiamentos, por exemplo. 
Os limites dos muros institucionais se rompem e temos novas modalidades de relações sem a mediação direta dos estabelecimentos de trabalho e educacionais. A educação à distância, portanto, poderia ser caracterizada como um modo de educação que se enquadra nos ditames de uma sociedade de controle em meio aberto.

As novas tecnologias poderiam ser problematizadas a partir de um controle modular, pois os muros da escola não confinariam mais o aluno, que estuda sem sair de casa em ambientes de interação, em um espaço virtual alargado e de intensa velocidade de circulação de informações praticamente instantâneas.

A educação como puro fluxo de comunicação volátil se torna uma demanda do mercado. A educação ao longo de toda a vida legitima a vivência de uma dívida nunca pagável do conhecimento transformado em mercadoria e instrumentalizado de forma utilitarista, conforme os interesses de grandes empresas.

A formação continuada rápida e sem burocracias, porém, declarada pelos seus defensores como de alta eficiência e eficácia, é um efeito deste processo de flexibilização das relações sociais e econômicas, em uma dinâmica de controle. As universidades ditas corporativas selam esta empreitada ao retirarem da universidade tradicional o monopólio da educação como debate na esfera pública sem pretensões de aplicação valorada pelo capital de modo direto.

[...] Mas atualmente o capitalismo não é mais dirigido para a produção, relegada com freqüência à periferia do Terceiro Mundo, mesmo sob as formas complexas do têxtil, da metalurgia ou do petróleo. É um capitalismo de sobreprodução. Não compra produtos acabados, ou monta peças destacadas. O que ele quer vender são serviços, e o quer comprar são ações. Já não é um capitalismo dirigido para a produção, mas para o produto, isto é, para a venda ou para o mercado. Por isso, ele é essencialmente dispersivo, e a fábrica cedeu lugar à empresa. [...] O serviço de vendas tornou-se o centro ou a "alma" da empresa. Informamos que as empresas têm uma alma, o que é efetivamente a notícia mais terrificante do mundo. O marketing é agora o instrumento de controle social, e forma a raça impudente de nossos senhores. O controle é de curto prazo e de rotação rápida, mas também contínuo e ilimitado. [...]. (DELEUZE, 1992b, p. 223-224)

Silva (1997) ressalta que os novos neoliberais têm difundido massivamente o ideário de uma educação funcionando como modelo de uma empresa, adentrando o campo do livre mercado e da livre iniciativa. Ele ainda destaca como o discurso publicitário tem abafado o político em termos de convencimento de uma suposta necessidade da redefinição dos modos de educar tecnicamente por meio de novas tecnologias educativas, baseadas em critérios de competência, 
produtividade, eficiência e qualidade. Cita os modelos de gestão chamados de "filosofia da qualidade total", divulgados no Brasil por Cosete Ramos, com toda uma "engenharia da instrução", tal como esta lógica foi batizada por sua idealizadora, com o apoio do Ministério da Educação e de Organizações multilaterais internacionais. Silva (1997) acrescenta que esta forma de educar tem sido fortemente marcada pelas exigências da indústria e do comércio e das regras do chamado empreendedorismo. O leitor poderá conferir a oferta massiva de cursos à distância como demanda industrial, por exemplo, consultando a página do Serviço Nacional de Aprendizagem (SENAC), na internet.

No Brasil, durante a consolidação da Nova República, com a abertura para a internacionalização e a privatização em massa das empresas públicas, desde a era Collor, expandiu-se a filantropia social, e se tornaram freqüentes o uso de termos, como: "empresa-cidadã", "responsabilidade social do setor privado", clamores pelo voluntarismo e associativismos, conforme aponta Oliveira (2003).

Várias empresas privadas têm oferecido formação aos seus funcionários, na modalidade de ensino à distância, via sistema "telecurso", nível fundamental e médio, muitas, usando o formato da Fundação Roberto Marinho e até em parceria com a mesma Fundação. Silva (1997) assinala que a Fundação Roberto Marinho, além de usar captação de recursos públicos para seus projetos ditos de "responsabilidade social", ainda opera mais do que uma prática educativa, pois difunde todo um ideário neoliberal.

Deste modo, a expansão do ensino à distância pode funcionar como um analisador social de uma sociedade de controle que vive sob o imperativo da venda de informações e de uma gerência deste processo em larga escala de acesso veloz à mercê de interesses do mercado.

Um exemplo mais concreto ainda desta realidade mercadológica e instrumental da educação como produto a ser vendido velozmente são as chamadas universidades corporativas. As grandes empresas, que pagavam cursos externos para seus funcionários, atualmente têm criado o que chamam de "universidades corporativas", ou seja, elas mesmas oferecem formação rápida e técnica internamente com poder de chancelar diplomas reconhecidos e de retirar do currículo tudo aquilo que um capitalista tecnocrata considerar descartável, não prático e pouco aplicável na educação escolarizada presencial e externa à empresa. Esta modalidade de educação atinge o auge do tecnicismo utilitarista.

\section{Educação, velocidade e política na sociedade em rede}

Para Virilio (1996), um analisador importante das mudanças que relatamos seria a desterritorialização da velocidade propiciada pelas novas tecnologias associadas aos sistemas políticos e econômicos, 
sustentando uma lógica da corrida competitiva que configura uma sociedade que ele nomeia de "dromocrática", que institui uma corrida política.

O fluxo da informação e da transformação dessa informação em conhecimento está no âmago do mandato da UNESCO de contribuir para a paz e segurança por meio da promoção da colaboração entre as nações. O benefício da participação na sociedade global da informação requer um consenso internacional dentro deste amplo mandato. O progresso da educação, ciência e cultura é fundamentalmente o de compartilhar informação e de criar novos meios de aprendizagem e conhecimento. (UNESCO, 2002, p. 274-5)

Inaugura-se uma ditadura do deslocamento e um estado de emergência constante que dispara controles sutis do tempo e do movimento. O deslocamento acontece não apenas no espaço territorial, mas se dá de forma acelerada no espaço virtual, conforme Virilio (1996).

A utilização de modernas tecnologias de educação à distância, em países da vastidão territorial do Brasil, possui o mais alto alcance, sobretudo na perspectiva de oferecer, a todas as pessoas, seja pelo processo formal ou informal, condições de aperfeiçoamento continuado. As transformações que se operam, em escala mundial, e que abarcam todos os setores das atividades humanas exigem educação continuada. Mais do que isso: exigem educação de qualidade - chave para a entrada em um novo patamar do desenvolvimento. A educação à distância permite colocar à disposição de todos conhecimentos dos mais atualizados, bem como, permite que cada cidadão programe sua própria aprendizagem, de acordo com suas condições e possibilidades. (UNESCO, 2002, p. 245)

Entra em cena um processo de encolhimento do espaço em termos de redução virtual das distâncias geográficas pela via da propalada revolução das telecomunicações, que criaram um sistema de rede de informações tão veloz, possibilitando o aparecimento de um Estado de Emergência. Instaura-se uma economia política das riquezas coextensiva à velocidade da circulação da informação (VIRILIO, 1996).

O elevado grau de competitividade ampliou a demanda por conhecimentos e informações. As mudanças que já se efetivaram ou as que estão em curso atingem a estrutura social, em sua totalidade, gerando incertezas crescentes quanto ao futuro. [...] Em decorrência, a educação passou a ocupar posição estratégica no processo de competitividade. Vários países têm procurado reformar seus sistemas de educação com o intuito de prepará-los para fazer face às novas demandas. (UNESCO, 2002, p. 21-2) 
Virílio (1996), ao analisar a relação entre política e velocidade, afirma que quem controla a velocidade controla tudo, o espaço e a informação; o que produz uma vertigem da aceleração sem igual. Trata-se de um estado de urgência em que tudo é engolfado pelo capital em sua versão mundial através do crescimento de redes finas e fluidas de informação circulando no espaço global para ampliar o próprio capital.

\begin{abstract}
De uns poucos centros de produtores de conhecimento, no passado, o mundo evoluiu para uma multiplicidade impressionante de instituições e pessoas que se dedicam ao avanço da ciência, da cultura e da tecnologia, nas diversas áreas do saber humano. A competitividade entre as nações, antes baseada no controle de fontes de matéria-prima e em mão de obra de baixo custo, fundamenta-se, hoje, na apropriação e produção de conhecimentos. Disso decorre a importância estratégica da educação, em todos os níveis e modalidades. Nenhum país alcançará êxitos significativos neste século se não conseguir organizar um sistema de educação de qualidade para todos. Da pré-escola aos estudos universitários e pós-graduados, sobressai a urgente necessidade de criarmos condições para um ensino de qualidade. (UNESCO, 2002, p. 45)
\end{abstract}

A gerência da informação por meio do controle político, econômico e temporal de sua difusão se transformou em imperativo do governo mundial, em nome da segurança e da competição entre as nações. Para tanto, a educação pautada no uso de novas tecnologias tornouse um dos dispositivos que ligou velocidade e política.

\title{
Considerações finais
}

Desta forma, entendo que tanto o desejo de provar numericamente a "eficácia da EAD" em contraposição a outras formas de educação, bem como a difusão de modos de expansão da EAD atendem, em grande parte, ao apelo por mercantilização de informação e por controles dos corpos via ambientes virtuais, tal como vem sendo realizado, no Brasil, nas últimas décadas, sob os ditames de organizações multilaterais gestoras dos mecanismos de segurança na ordem política internacionalizada e de empresários ávidos por expandir seus lucros.

O Estado se tornou o mediador da proliferação de formatos de educação à distância como estratégia biopolítica, de controle social e de governo da velocidade dos fluxos informacionais em funcionamento no formato de rede virtual.

Concluímos temporariamente este texto que teve um objetivo de fazer uma ontologia do presente enquanto uma análise histórica de nós mesmos, ressaltando de certo modo o que estamos fazendo em nossa atualidade. 


\section{Referências Bibliográficas}

BRASIL. Instituto Nacional de Estudos e Pesquisas Educacionais Anísio Teixeira. In: Educação a Distância cresce mais ainda entre os cursos superiores. Brasília, 2007. Disponível em http://www.inep.gov.br/imprensa/noticias/censo/superior/news07_01 htm. Acesso em: 28 ago. 2009.

DELEUZE, G. Controle e devir. In: janeiro: Editora 34, 1992 (a). p. 209-21̄8.

Conversações. Rio de . Post-scriptum sobre as sociedades de controle. In: DELEUZE, G. Conversações. Rio de janeiro: Editora 34, 1992 (b). p. 219-226. FOUCAULT, M. Nascimento da Biopolítica. São Paulo: Martins Fontes, 2008.

OLIVEIRA, F. de Política numa era de indeterminação: opacidade e reencantamento. In: SILVA, F. T. da; NAXARA, M. R. C. \& CAMILOTTI, V. C. (orgs.) República, Liberalismo, Cidadania. Piracicaba/SP: UNIMEP, 2003. p. 191-217.

PELBART, P. P. A vertigem por um fio: políticas da subjetividade contemporânea. São Paulo: Iluminuras / FAPESP, 2000.

PETERS, M. Governamentalidade Neoliberal e Educação. In: SILVA, T. T. da. O sujeito da educação. Estudos foucaultianos. 5ạ. Ed. Petrópolis: Vozes, 2002. p. 211-224.

Relatório Jacques Delors. Educação para o século XXI: um tesouro a descobrir. Brasília: Cortez/MEC/UNESCO, 1999.

SILVA, T. T. A "nova" direita e as transformações na pedagogia da política e na política da pedagogia. In: GENTILI, P. A. A.; SILVA, T. T. da (orgs.). Neoliberalismo, qualidade total e educação. Visões críticas. 5ạ. Ed. Petrópolis: Vozes, 1997. p. 11-27.

VIRILIO, P. Velocidade e política. São Paulo: Estação Liberdade, 1996.

UNESCO. Construção e identidade: as idéias da UNESCO no Brasil. Brasília: UNESCO, 2002.

\section{Endereço para correspondência}

Flávia Cristina Silveira Lemos

Programa de Pós-graduação em Psicologia/IFCH/UFPA, Rua Augusto Corrêa, n. 01, Guamá, CEP 66.075-110, Belém-PA, Brasil

Endereço eletrônico: flavialemos@ufpa.br

Recebido em: 23/03/2009

Aceito para publicação em: 23/09/2009

Acompanhamento do processo editorial: Ana Maria Lopez Calvo Feijoo

Notas

* Psicóloga pela UNESP-Assis; Mestre em Psicologia e Sociedade pela UNESP-Assis; Doutora em História e Sociedade pela UNESP-Assis. 